\title{
Investigation of temperature profile for nano fluid, pure water, ammonia and methanol in a heat pipe
}

\begin{abstract}
The authors investigate thermal performance of pure water, nanofluid, ammonia and methanol on the heat pipe with $18 \mathrm{~cm}$ in length and $0.01 \mathrm{~m}$ in diameter in this paper, approximately. The average difference between temperature profile of ethanol and methanol is about $36.4 \%$ in this case. The three polynomials with second order are defined in this study. The fluid passes through the heat pipe, experimentally. The curve fitting and regression of the experimental correlations show the accuracy of three curves are proper and so the predictions of temperature profile in the external zones are feasible.
\end{abstract}

Keywords: pure water, thermal resistance, ethanol, methanol, heat pipe, nano fluid
Volume 3 Issue I - 2019

\section{Farshad Farahbod}

Department of Chemical Engineering, Islamic Azad University, Iran

Correspondence: Farshad Farahbod, Department of Chemical Engineering, Firoozabad Branch, Islamic Azad University, Firoozabad, Iran, Tel 987।38736802,

Email farahbod.f@srbiau.ac.ir

Received: February 17, 2019 | Published: March 22, 2019

\section{Introduction}

Generally, attempts of humans during the industrial history have been tended to higher heat transfer rates and making heat exchangers in smaller size. ${ }^{1}$ Although the metallic particles suspended in the fluids have higher thermal conductivities and had been proposed to heat transfer augmentation in the heat exchangers, but they also are responsible of erosion corrosion, pressure drop and pipe blockage. ${ }^{2}$ Therefore, adding particles in millimetres or even micrometres size, have encountered problems. Suspensions with millimetre or micron sized particles are famous to cause severe problems in heat transfer apparatus. However, particles in large size tend to quickly settle out of suspension and cause to severe clogging by passing through micro channels. Thereby, the pressure drop increases severely. ${ }^{3}$ Furthermore, the abrasive actions of these particles cause to the erosion of pipelines and industrial equipments. Nowadays, developing technology represents the utilization of nanofluids as working fluids in heat transfer equipments. 'Nanotechnology" is one of the important branches which uses substances in nano size in many revolutionary variations that can significantly improve device performance which relates to engine cooling systems, petroleum and chemical plants, technology of communication, resistor materials, sensor applications, drug delivery, pharmaceutical industries and several area of practical importance. ${ }^{4}$ With the rapid development of this area of science, nano materials have been used into the heat transfer subfields as nanofluids which are produced by dispersing nano particles of metals in the working fluids. ${ }^{5}$ Heat pipes are utilized in cooling purposes in several fields of technology, excessively. Since these parts are low in cost so they are named highly reliable equipments. Their usage in high power cooling applications has been limited to custom applications requiring either low thermal resistance and/or having a severely restricted enclosure field. The thermal performance of heat pipe as one type of highly effective heat transfer part in heat exchange apparatus can be improved by using nanofluids. ${ }^{6}$ There are different methods for providing the $\mathrm{SnO}$ nanoparticles which are briefly as; a) dissolving $\mathrm{Sn}$ salt in the deionized water to make a precursor solution; b) heating deionized water; c) adding solid alkali salt to the precursor solution to make a dispersion of $\mathrm{SnO}$ nanoparticles; and d) separating the $\mathrm{SnO}$ nano particles by solid-liquid separation and washing them with deionized water. Highly pure, crystalline $\mathrm{SnO}$ nanoparticles with spherical appearance and size distribution of 50 to $60 \mathrm{~nm}$ (approximately) can be prepared quickly and at large scale and very low cost application of inexpensive materials via a stable low-temperature process, without using a dispersant. ${ }^{6,7}$ The associated low-temperature, normal-pressure process produces few harmful materials and may be easily employed for preparing of stannum oxide nanoparticles. Surely, nano fluid is a new type of heat working fluid, which is made by adding nano-level substances such as metallic, nonmetallic or polymeric solid particles into the liquid in a certain method and ratio. ${ }^{8,9}$

In this paper, the thermal performance of pure water, nanofluid, ammonia, ethanol and methanol are investigated in this paper. In addition, the thermal resistance of pure water and nanofluid is evaluated in the different heat fluxes. ${ }^{10}$

\section{Materials and methods}

The heat pipe with determined structure is used for evaluation of temperature distribution of pure water, nanofluid with different concentrations, ammonia, methanol and ethanol in the heat pipe.

\section{Results and discussion}

\section{Temperature distribution of the tube wall}

The temperature distributions are measured in different positions of heating pipe for different types of fluids. The pure water, nanofluid, ammonia, ethanol and methanol as operating fluids are used in this work. In this paper $30 \mathrm{Watt}$, 40Watt, 50Watt and 60Watt are selected as input power to heat pipe.

\section{Solutions contain $54 \mathrm{~nm}$ metal oxide particles}

The Figure $1 \&$ Figure 2 show the values of heat pipe wall temperature which ammonia and ethanol pass through it. In these experiments the fluid pass through a pipe which is exerted by different values of power adjusted in $30 \mathrm{~W}, 40 \mathrm{~W}, 50 \mathrm{~W}$ and $60 \mathrm{~W}$. All the results show the temperature profile of different basic fluids in the heat pipe for evaluation of performance of heat pipe in different industries applications. In addition, the obtained results indicate that the concentration of 50 nano particles is the effective amount of 
metal oxide and keeps the pipe wall temperatures in the optimum values. The experiments show the higher power cause to the higher convective heat transfer and the lower temperature profile, ultimately. More details are achieved in the following Figures.

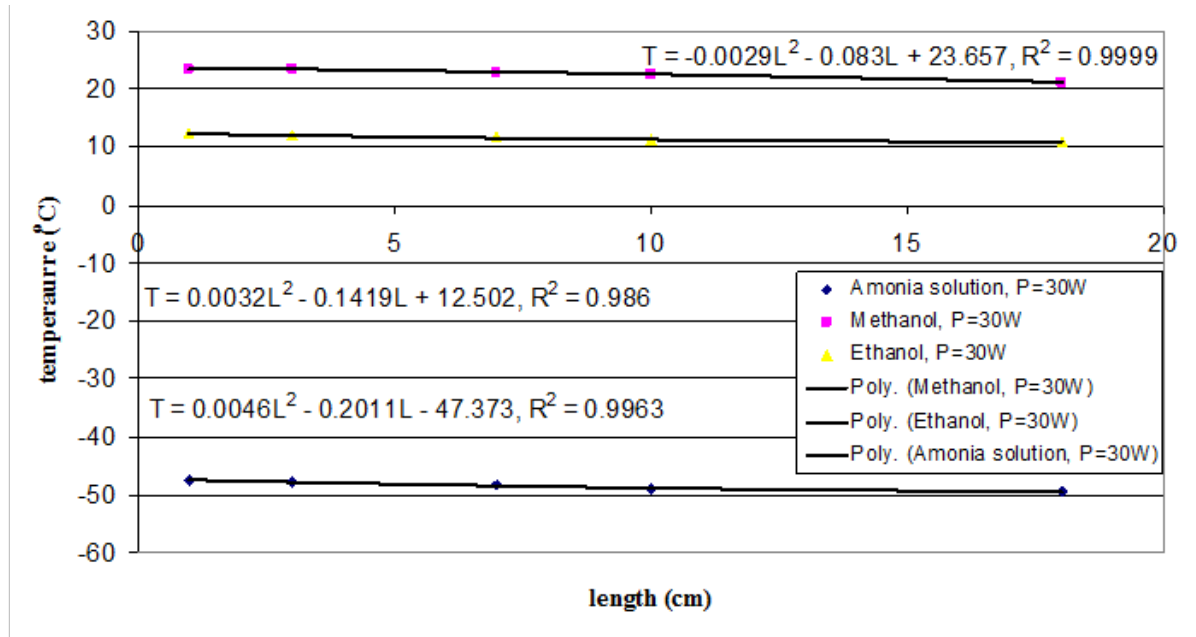

Figure I Temperature profile in the length of heat pipe.

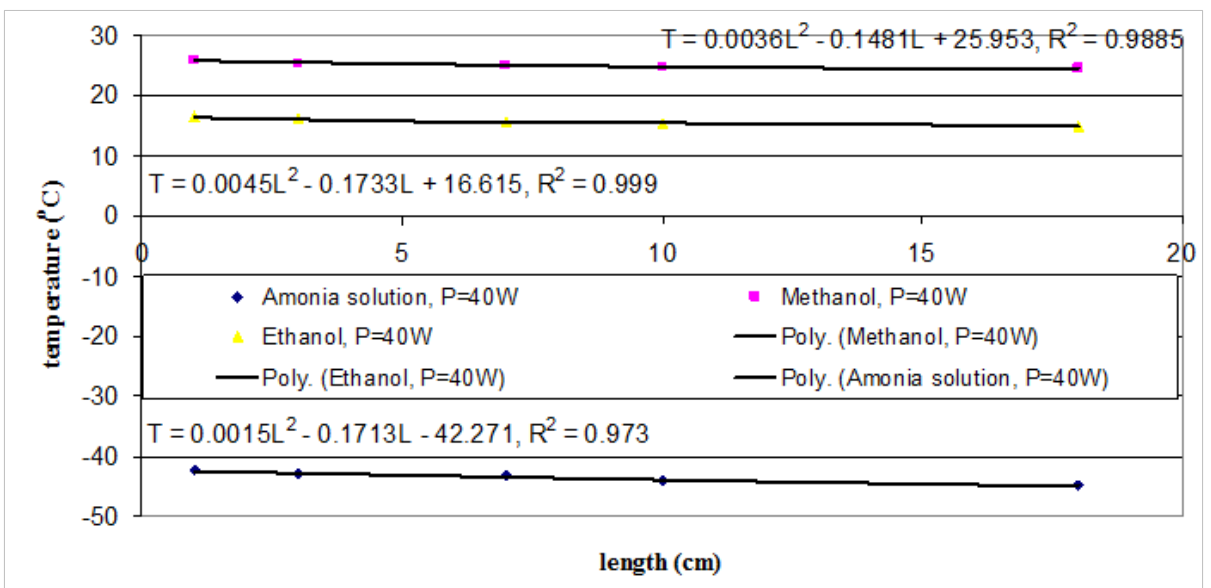

Figure 2 Temperature profile in the length of heat pipe.

The Figure 1 illustrates that the wall temperature of pipeline contains ammonia solution, methanol and ethanol. The results are evaluated for $30 \mathrm{~W}$. The obtained results show, the temperature interval for methanol is 21.24 to 23.56 centigrade degree. In addition, the temperature interval for ethanol is 11.01 to 12.34 centigrade degree. The results show the average difference between the temperature profile for methanol and ethanol is $47.08 \%$, approximately. The experimental result show the temperature profile for ethanol is lower than methanol. The temperature profile for ammonia is negative as shown in the (Figure 1).

Temperature distribution profiles for ammonia, methanol and ethanol in $40 \mathrm{~W}$ as input power is shown in the Figure 2. The average difference between temperature profile of ethanol and methanol is about $36.4 \%$ in this case. The three polynomials with second order are defined in this study. The curve fitting and regression of the experimental correlations show the accuracy of three curves are proper and so the predictions of temperature profile in the external zones are feasible.

\section{Conclusion}

Investigations about the performance of heat pipes contain nano ferric oxide is done experimentally, in this wok. At the first, the nano metal oxide (ferric oxide) is made and nano fluid utilizes by dispersing the particles in nano size in pure cooling water. The results are evaluated for $30 \mathrm{~W}$. The obtained results show, the temperature interval for methanol is 21.24 to 23.56 centigrade degree. In addition, the temperature interval for ethanol is 11.01 to 12.34 centigrade degree. The results show the average difference between the temperature profile for methanol and ethanol is $47.08 \%$, approximately. The average difference between temperature profile of ethanol and methanol is about $36.4 \%$ in this case. The three polynomials with second order are defined in this study. The curve fitting and regression of the experimental correlations show the accuracy of three curves are proper and so the predictions of temperature profile in the external zones are feasible.

\section{Acknowledgments}

None.

\section{Conflicts of interest}

The author declares there is no conflicts of interest. 


\section{References}

1. Nadeem S, Mehmood Rashid, Sher Akbar Noreen. Non-orthogonal stagnation point flow of a nano non-Newtonian fluid towards a stretching surface with heat transfer International. Journal of Heat and Mass Transfer. 2013;57(2):679-689.

2. Cho T, Baek I, Lee J, et al. Preparation of nano-fluids containing suspended silver particles for enhancing fluid thermal conductivity of fluids. Journal of Industrial and Engineering Chemistry. 2005;11:400406 .

3. Wang Xian-Ju, Li Hai, Li Xin-Fang, et al. Stability of $\mathrm{TiO}_{2}$ and $\mathrm{Al}_{2} \mathrm{O}_{3}$ nanofluids. Chinese Physics Letters. 20011;28(8):086601.

4. Taghiyari Hamid Reza. Effects of Nano-Silver and Nano-Zycosil on Mechanical Strength of Heat, Vapor, and Dry-Ice-Treated Biscuit and Dovetail Medium-Density Fiberboard Miter Joints. Materials \& Design. 2013;51:695-700.

5. Bhuwakietkumjohn N, Rittidech S. Internal flow patterns on heat transfer characteristics of a closed-loop oscillating heat-pipe with check valves using ethanol and a silver nano-ethanol mixture. Experimental Thermal and Fluid Science. 2010;34(8):1000-1007.
6. Wei WC, Tsai SH, Yang SY, et al. Effect of nano-fluid on heat pipe thermal performance. International Conference on Heat Transfer. Thermal Engineering and Environment. 2005;2:115-117.

7. Wei WC, Tsai SH, Yang SY, et al. Effect of nano-fluid concentration on heat pipe thermal performance. IASME Transactions. 2008;2:1432-1439.

8. Kabeel AE, Abou El Maaty T, Samadony Y El. The effect of using nano-particles on corrugated plate heat exchanger performance. Applied Thermal Engineering. 2013;52(1):221-229.

9. Ferkl Pavel, Pokorny Richard, Bobak Marek, et al. Heat transfer in onedimensional micro- and nano-cellular foams. Chemical Engineering Science. 2013;97(28):50-58.

10. Jang SP, Choi SUS. Role of Brownian motion in the enhanced thermal conductivity of nanofluids. Applied Physics Letters. 2004;84(21):43164318. 